\title{
CAUSAlidade E NATUREZA NA COSMOLOGIA DE TOMÁS DE AQUINO ${ }^{1}$
}

Evaniel Brás dos Santos (Unicamp) ${ }^{2}$

evanielbras@yahoo.com.br

Resumo: A concepção de causalidade de Tomás de Aquino, sobretudo vinculada às noções de criação e natureza, fundamenta sua cosmologia presente na Summa contra gentiles. Duas teses são primordiais para a referida cosmologia. A primeira afirma que a causalidade divina impõe ordem sobre o mundo. A segunda, por sua vez, sustenta que o conjunto dos astros, o céu, rege e move a região sublunar, o que ocorre necessariamente devido à causalidade divina. Há, portanto, uma articulação concebida por Tomás entre as duas teses. Explicitar tal articulação é o propósito deste artigo. Para tanto, investigo como Tomás compreende e vincula as noções de causalidade, criação e natureza de modo a assegurar, por um lado, a criação divina e, por outro, a operação própria dos entes naturais, dentre os quais se destaca o céu que, devido à locomoção contínua, confere as condições para a efetivação das potencialidades dos entes sublunares.

Palavras-chave: Filosofia Medieval; física aristotélica; física medieval.

\section{INTRODUÇÃO}

O contexto no qual os filósofos do século XIII do ocidente latino elaboraram suas cosmologias contribui no direcionamento das questões formuladas e respondidas por eles. Porém, ele não determina o que cada filósofo julga como essencial em sua concepção de mundo. Isso pode ser evidenciado, dentre outros, pela leitura da Summa contra gentiles (SCG) de Tomás de Aquino, sobretudo quando o autor,

\footnotetext{
${ }^{1}$ Recebido: 30-01-2014/ Aprovado: 01-08-2015/Publicado on-line: 31-08-2015.

${ }^{2}$ Evaniel Brás dos Santos é Doutorando em Filosofia pela UNICAMP, Campinas, SP, Brasil.
} 
por razões filosóficas, se mantém conceitualmente contra a tentativa de imposição da concepção de mundo de outrem, o que ocorreu pelas condenações parisienses de 1270, nomeadamente quanto às noções de criação e natureza vinculadas à quarta proposição condenada. Embora este artigo não tenha por escopo relacionar diretamente a possível discussão entre Tomás e as condenações, nem mesmo entre ele e os autores que de algum modo são visados nas condenações, ${ }^{3}$ a menção a este evento funciona como via para se perceber a ênfase conferida pelo próprio Tomás a uma tese central de sua cosmologia, a saber: os entes da região sublunar necessitam, para existir e operar, da locomoção do conjunto dos astros, o céu. Nesse sentido, o céu é entendido por Tomás como o primeiro agente da natureza que, ao operar ininterruptamente sobre a região sublunar, conserva a existência dos entes desta região e viabiliza suas operações

A noção de natureza e sua relação com a noção de criação no século XIII fora objeto de debates e punições. Isso é manifesto, sobretudo, pelas condenações que o bispo de Paris Étienne Tempier promulgou em 1270 e 1277. Das treze proposições condenadas em 1270, a quarta diz: "Tudo o que ocorre aqui no mundo sublunar está submetido à necessidade dos corpos celestes". (WEISHEIPL 1975, p. 276). Essa condenação é reforçada em 1277, pois, das duzentas e dezenove proposições condenadas, a de número 156 reza: "Se o céu parasse, o fogo não atuaria, pois seria removido, porque a natureza cessaria de operar" (GRANT 1987, p. 16) .

Pelo que se nota, as condenações manifestam certa

\footnotetext{
${ }^{3}$ Sobre esta discussão, ver: Torrell 2004, p. 209-287; Weisheipl 1975, p. 241-292.
} 
concepção de mundo e de natureza que, como explicitarei mais à frente, difere notavelmente daquela presente em Tomás. Com efeito, ao negar que os entes sublunares necessitam da locomoção celeste para operar, as proposições indicam, por um lado, a possível ausência do primeiro agente da natureza que coopera ou mesmo viabiliza a operação dos entes sublunares e, por outro, certa preocupação de que a necessidade apontada implicaria em negar a operação divina na região sublunar. ${ }^{4}$ Nessa medida, o sentido de "necessidade" presente nas duas condenações se refere, respectivamente, a duas discussões. A primeira, mais restrita, se atém à possibilidade do céu determinar a vontade e destino do homem. A segunda, mais geral, diz respeito à natureza entendida como princípio de movimento e de repouso e, ademais, de seu vínculo com a operação divina de criação. Nesse aspecto mais geral, a discussão centra-se na seguinte questão: se a locomoção do céu cessasse, cessariam imediatamente o movimento e a mudança na região sublunar? A referida condenação conclui pela negativa. Porém, a resposta a partir da SCG I-III de Tomás, conclui positivamente .

Cumpre observar, ademais, que, embora o término da redação da SCG tivesse ocorrido entre 1264-1265 (TORRELL 2004, p. 388), no interior da opera a SCG era bastante apreciada pelo autor que não somente a revisou em várias ocasiões, ${ }^{5}$ mas também ao longo da carreira lhe

\footnotetext{
${ }^{4}$ Como bem apontou Grant $(1987,16):$ "[...] o bispo de Paris não deixou nenhuma dúvida sobre sua aversão à ideia de que as ações terrestres dependem totalmente dos movimentos celestes, e, por implicação, independem das ações de Deus. Como consequência, era preciso admitir, ao menos na diocese de Paris, que se os movimentos celestes cessassem, o fogo poderia atuar por seu próprio poder queimando o linho".

5 "A Suma contra gentios é a segunda grande obra pessoal de Tomás, que a releu, modificou e corrigiu em várias ocasiões”. (TORRELL 2004, p. 388). Ver também: Torrell 2004, p. 113-136.
} 
faz remissão (cf. idem, 122), o que indica que Tomás manteve até o fim de sua carreira as posições já estabelecidas na SCG. Enfatizo, dentre as posições de Tomás, aquela da necessidade do céu na região sublunar, e isso a despeito de ter conhecimento da condenação mencionada de 1270, pois, Tomás lecionava na Universidade de Paris desde 1268, vindo a finalizar suas atividades aí em 1272 (cf. ibidem, 288) .

Embora tivesse a oportunidade de revisar sua posição, Tomás não o fez, razão pela qual, ao menos virtualmente, ele também fora atingido por algumas proposições condenadas. ${ }^{6}$ A tese central que fez Tomás manter sua posição refere-se à sua concepção de causalidade, sobretudo no que tange ao seu vínculo com as noções de criação e natureza. Nesse sentido, o propósito deste artigo é explicitar como Tomás articula tais noções de modo a assegurar, por um lado, a criação divina e, por outro, a operação própria dos entes naturais, dentre os quais se destaca o céu que, devido à locomoção contínua, confere as condições para a efetivação das potencialidades dos entes sublunares .

\section{CRIAÇÃO E PROVIDÊNCIA DIVINA}

A concepção de Tomás de causalidade do céu se dá de dois modos. Tomás na SCG confere um tratamento sobre esse assunto em âmbito particular e geral. A consideração particular, tratada na SCG, III, 84-87 designa a operação de al-

\footnotetext{
${ }^{6}$ Notadamente pela quarta proposição apresentada acima e pela quinta proposição, qual seja, "Que o mundo é eterno" (WEISHEIPL 1975, p. 276). Sobre a discussão do envolvimento de Tomás com a quinta proposição, ver: Torrell 2004, p. 215-218. Sobre a discussão geral das noções de criação e eternidade em Tomás, inclusive com amplas referências bibliográficas, ver: Santos 2013. Quanto à discussão geral da proposição 4, seu vínculo com a proposição 156 e, ademais, os vários filósofos atingidos ou comprometidos com essa proposição até o período dos Conimbricenses, ver: Grant 1987, p. 1-23.
} 
guns entes particulares, ou seja, a operação circunstancial. Nesse aspecto, Tomás afirma que nem tudo o que ocorre na região sublunar é efeito direto do céu, pois como pode haver causas intermediárias entre o céu e determinados efeitos, se essas causas falharem ou mudarem o seu curso, não se seguirá o efeito que o céu poderia produzir. Ademais, como o céu não possui a potência para produzir a alma humana, ele não opera diretamente sobre ela, não tendo, portanto, influência sobre a vontade humana.?

A consideração geral, por sua vez, tratada na SCG, II, 630 e III, 64-82, centra-se nas seguintes discussões: (a) a autonomia divina ao operar e a necessidade absolu$\mathrm{ta} /$ condicional entre os entes naturais; (b) a natureza enquanto princípio de movimento; (c) a constituição dos entes naturais .

Esses assuntos estão subsumidos na discussão que articula as noções de criação e providência divina. A noção de criação, por ser compreendida pela noção de relação, referese à causa e ao efeito. Dizendo respeito à causa, "criação" significa operação sem movimento ou mudança. Dita tendo como referência o efeito, a noção de criação tem o mesmo sentido da noção de mundo: o conjunto de todas as coisas. Nessa medida, o que se investiga é a constituição do efeito, isto é, a coisa mesma que se caracteriza pela dependência ontológica ao seu princípio.

Essa dependência é explicitada por Tomás no segundo livro do Scriptum super libros Sententiarum:

Criação, na medida em que diz respeito ao efeito, implica duas coi-

\footnotetext{
${ }^{7}$ Uma das razões pelas quais o céu não determina a vontade humana se dá pelo postulado segundo o qual a alma humana é criada diretamente pela divindade e introduzida na matéria devidamente disposta na mulher. Sobre essa discussão, ver: Bazán 2011, p. 515-569.
} 
sas. Primeira, que a criatura não provenha de qualquer matéria preexistente; e, desse modo, criação difere completamente de todo tipo de mudança ou movimento que sempre envolve um substrato [...]. Segunda, criação implica na criatura ser após não ser; não, porém, de acordo com qualquer sucessão temporal, como se a criatura em algum momento não existisse e, então, passasse a existir, mas de acordo com a prioridade por natureza ou por essência, uma vez que tem existência somente por meio do criador. Pois, o que um ente tem por si mesmo, por natureza lhe pertence antes daquilo que lhe é doado por uma causa extrínseca [...]. De acordo com essas duas considerações, se diz que a criação se dá a partir do nada. (In Sent. II, d. I, q. I, a. 2, resp.)

A primeira característica mencionada, qual seja, não provir de matéria preexistente, diferencia o vir à existência do efeito da mudança que o efeito pode sofrer, seja a substancial, seja a alteração. Essa diferença se dá porque a mudança envolve necessariamente um substrato material. Esta é a razão pela qual, na SCG, II, 17, 953 Tomás escreve: “[...] vê-se que a criação é uma certa mudança somente segundo nosso modo de entender, isto é, enquanto o nosso intelecto concebe uma só e mesma coisa como não existindo antes, mas existindo depois". Portanto, a concepção da mudança, por referir-se ao antes e ao depois, só pode ser atestada em virtude da percepção humana de eventos naturais como temporais, uma vez que a concepção da mudança faz referência ao antes e ao depois. Nesse sentido, por captar o antes e o depois dos eventos, a percepção não capta o instante que, nesse contexto, significa a parte indeterminada do tempo. Sendo assim, o "vir à existência do efeito", embora concebível, não é representado precisamente pelo intelecto humano, sua representação é imprecisa e se dá como mudança. A segunda característica, por sua vez, afirma que o não ser, o nada, antecede o ser nos entes. Essa antecedência é entendida por Tomás como sendo por natureza, isto é, 
denota que aquilo que pertence a um ente, por ele mesmo, lhe é mais basilar do que o recebido de um outro. Portanto, tratando-se da existência, um ente distinto da divindade não possui, por si mesmo, a existência, pois o que lhe pertence, por si mesmo, é a não existência, o não ser.

O não ser intrínseco que precede por natureza ao ser não é entendido como uma condição dada pela natureza:

[...] é preciso dizer que aquela mutabilidade que pertence a toda criatura não se dá segundo algum movimento natural, mas segundo a dependência para com Deus, pelo qual, se fosse abandonada a si, ficaria desprovida daquilo que é. Assim, esta dependência pertence antes à consideração do metafísico do que à do físico. (Super Boetium De Trinitate, questão 5 , artigo 2, ad7)

A mutabilidade afirmada diz respeito ao não ser intrínseco à criatura, razão pela qual, a ela, precede permanentemente, por natureza, o não ser e a divindade, o que conduz Tomás a sustentar dois postulados. Primeiro, que a noção de criação deve ser tratada primariamente pela metafísica na categoria da relação. Segundo, que a noção de criação entendida como efeito pertence ao tratamento sobre a providência divina. No primeiro postulado, Tomás sustenta que, pelo fato da categoria da relação ser tratada tanto na metafísica, quanto na física, as considerações desta auxiliam no tratamento metafísico da relação entre a divindade e o mundo (cf. Idem, qq. 5-6). Esse auxílio se dá na medida em que a física estabelece que há relação efetiva entre causa e efeito, isto é, que há influência mútua nas operações das causas naturais do mundo sublunar, uma vez que essas operações se configuram como atualização de potências, na causa e no efeito. Todavia, embora auxilie a metafísica, o tratamento da física sobre a relação entre causa e efeito pressupõe o tratamento da metafísica sobre a constituição 
mesma do mundo, uma vez que a relação entre as causas naturais pressupõe a operação divina de criação. No segundo postulado, por sua vez, Tomás estabelece que, como a operação de criação é atribuída exclusivamente à divindade, nessa operação não há, em hipótese alguma, cooperação de causas segundas, os instrumentos (cf. SCG, II, 21).

A discussão sobre o vínculo entre a operação divina e os instrumentos está inserida no contexto da distinção entre criação e conservação. Para distinguir a operação que essas duas noções significam, Tomás emprega as expressões "primeira instituição do mundo" (Summa theologiae, I parte, questão 74, artigo 1, sed contra) e "primeira instituição da natureza” (ST, Ia, q. 67, a. 4, ad3) para designar o sentido da operação divina de criação. Quanto à conservação, ele emprega a expressão "contínua influência": "O modo pelo qual [a divindade] conserva as coisas no ser é pela contínua influência do ser" (ST, Ia, q. 104, a. 1, ad4).

O termo "primeira" atribuído à instituição do mundo e da natureza denota o estado de ambos antes de qualquer processo e aperfeiçoamento realizado por eles mesmos. Nesse caso, emprega-se o termo "criação". Uma vez que eles mesmos iniciam algum processo e aperfeiçoamento, não se emprega "criação", mas sim o termo "conservação". Nessa medida, a conservação refere-se ao efeito já instituído:

[...] Deus é causa primeira de todas as coisas. Logo, é necessário que Deus esteja para as espécies das coisas como, na natureza, o gerador está para a geração, da qual ele é causa por si. Cessa a geração ao cessar a operação do gerador. Portanto, cessariam todas as espécies das coisas, se a operação divina cessasse. Logo, Deus, por sua operação, conserva as coisas no ser. (SCG, III, 65, 1060)

Tomás compara a operação de conservação com a de geração. Primeiramente, é dito que a divindade, porque cria 
as espécies, as conserva como causa primeira. Nesse sentido, conservação pressupõe criação. Posteriormente, Tomás afirma que a geração possui sucessão, pois se dá no tempo, ou seja, uma vez que o gerador gera seu efeito, cessa a geração. Ademais, o efeito gerado só depende temporalmente do gerador, isto é, enquanto ocorre a geração, pois, terminada esta, o efeito é independente do gerador. Diferentemente, as espécies mesmo depois de criadas no ser, permanecem dependentes da conservação:

Como são muitas as causas ordenadas, é necessário que o efeito dependa, em primeiro lugar e principalmente, da causa primeira; depois e secundariamente, de todas as causas intermediárias. Portanto, a causa primeira é principalmente o que conserva o efeito, secundariamente todas as causas intermediárias e tanto mais quanto mais elevada for a causa e mais próxima da primeira causa. Por essa razão atribuem-se às causas superiores, mesmo entre as coisas corporais, a conservação e permanência das coisas. [...] o primeiro movimento diurno é causa da continuidade da geração; o segundo movimento, isto é, o movimento zodiacal, causa da diversidade quanto à geração e à corrupção. Da mesma forma os astrônomos atribuem a Saturno, o planeta supremo, as coisas fixas e permanentes. Portanto, deve-se dizer que Deus conserva certas coisas no ser por meio de outras causas. (ST, Ia, q. 104, a. 2, resp.)

\section{A conservação do efeito pela divindade se dá sem e com instrumentos. ${ }^{8}$ Sem instrumentos na medida em que o efei-}

\footnotetext{
${ }^{8}$ É importante enfatizar que, no contexto da discussão sobre a instrumentalidade dos entes, Tomás se opõe ao que ele julga ser a concepção equivocada de Avicena sobre a relação entre a causa primeira, a causa segunda e o efeito: "Assim, alguns opinaram que, embora a criação seja ação própria da causa universal, algumas das causas inferiores, agindo pela virtude da causa primeira, poderia criar. Dessa forma, Avicena afirmou que a primeira substância separada, criada por Deus, cria outra depois de si, tanto a substância do orbe como sua alma; e que a substância do orbe cria a matéria dos corpos inferiores. [...]. Porém, isso é impossível. Porque uma causa segunda instrumental não participa da ação da causa superior senão quando, por algo que lhe é próprio, age como disposição para produzir o efeito do agente principal. Se, portanto, nesse caso nada fizesse do que lhe é próprio, seria inútil utilizá-lo para agir. Não haveria, pois, necessidade de existir determinados instrumentos para produzir determinadas ações. [...]. O efeito próprio da criação divina é o ser absoluto, o qual é pressuposto por todos os outros efeitos. Assim, nenhum outro agente Cont.
} 
to não tem o princípio de movimento, a saber, as inteligências (anjos). ${ }^{9}$ Com instrumentos, por sua vez, quando o efeito tem o princípio de movimento (cf. SCG, III, 78). Ademais, porque não tem a disposição de, por si mesmo, se manter na existência depois da operação de criação, o efeito necessita ou só da divindade ou dela e de outro efeito para subsistir. Tomás enfatiza, na passagem citada, a conservação daquilo que é passível de movimento e mudança, a saber, os entes da região sublunar, a qual se dá pelos astros que realizam o movimento diurno e o zodiacal. Portanto, os astros medeiam a operação divina que conserva seu ato criador e a recepção do efeito na região sublunar .

\section{CAUSA PRIMEIRA UNIVERSAL, CAUSAS SEGUNDAS UNIVERSAIS, CAUSAS PARTICULARES}

O sentido da noção de causalidade que vincula discussões de física e metafísica subsume as razões pelas quais Tomás manteve sua posição mesmo após a condenação de 1270 . As razões podem ser nomeadas de dois modos: (i) quanto à causa universal do ser; (ii) quanto às causas particulares das determinações do ser:

Os efeitos são proporcionais às suas causas, de modo que atribuímos aos efeitos atuais causas atuais, e aos efeitos em potência, causas em potência. Semelhantemente, os efeitos particulares, às causas particulares e os universais, às causas universais [...]. Assim, o ser é a primeira coisa causada, o que é evidente, devido à sua natureza universal. Por conseguinte, a causa própria do ser é o primeiro agente universal, que é Deus. Os outros agentes não são simplesmente causa do

pode operar dispositiva e instrumentalmente em vista desse efeito, pois a criação não se dá a partir de algo pressuposto que poderia dispor-se pela ação de um agente instrumental. Por conseguinte, é impossivel que a alguma criatura convenha criar, nem por virtude própria, nem instrumentalmente ou por delegação". (ST, Ia, q. 45, a.5, resp.).

${ }^{9}$ Ver: SCG, III, 64-66; 75-81. 
ser, mas de ser determinado; como a causa de um homem, ou a causa de uma coisa branca. O ser é simplesmente causado por criação, que não pressupõe coisa alguma, porque uma coisa que esteja fora do ser não pode simplesmente preexistir. Por outras operações faz-se este ou aquele ente. (SCG, II, 21, 972)

Tomás, na passagem citada, versa sobre a causa primeira universal, a divindade, as causas segundas universais, isto é, as inteligências e o céu, ${ }^{10}$ e as causas particulares, os entes sublunares, "este homem" ou "esta coisa". A divindade é compreendida como a primeira causa universal não somente porque opera sem substrato prévio, ${ }^{11}$ mas também porque fornece as condições para a operação das outras causas, uma vez que confere o ser a todas as coisas. É nesse sentido que o ser é tido como "simplesmente causado por criação" (simpliciter per creationem causatur), donde ele ser compreendido tanto como "a primeira coisa causada" (esse est causarum primum) quanto como o efeito mais universal (ratione communitatis) da primeira causa universal. Por conseguinte, qualquer outra causa não se configura como causa primeira universal do ser, porque pressupõe a operação divina. Nessa medida, as causas universais segundas e as particulares funcionam como instrumentos que a divindade se utiliza, seja para conservar o ser, no caso do céu, cuja locomoção contínua é conservada pelas inteligências (cf. SCG, III, 23), seja para propagar o ser (cf. SCG, III, 64), no caso dos entes sublunares gerados, ou seja, o vir a ser "deste ente" (homem).

$\mathrm{O}$ instrumento pode ser compreendido a partir da relação entre um agente superior, um agente inferior e a produção do efeito:

\footnotetext{
${ }^{10}$ Ver também: SCG, III, 23.

${ }^{11}$ Cf. SCG, II, 16-17.
} 
Para qualquer agente deve-se considerar duas observações: a coisa que age [sua natureza] e a virtude pela qual age [sua operação], como o fogo que aquece pelo calor. Assim, a virtude do agente inferior depende da virtude do agente superior, enquanto este dá àquele a virtude mediante a qual age, ou a conserva, ou também a aplica na operação. É o caso do artífice que aplica o instrumento para o efeito próprio, do qual, no entanto, não dá a forma, segundo a qual o instrumento opera, nem a conserva, mas apenas lhe dá o movimento. É, pois, necessário que a ação do agente inferior não proceda só de si mesmo por virtude própria, mas também proceda da virtude de todos os agentes superiores. Opera, pois, em virtude de todos eles. E como se verifica que o mais inferior dos agentes é imediatamente operativo, também a virtude do primeiro agente é imediatamente produtiva do efeito, uma vez que a virtude do agente inferior não tem donde produzir o efeito por si mesma, mas o produz pela virtude do agente imediatamente superior. E, assim, a virtude do agente superior manifesta-se produtiva por si mesma do efeito como causa imediata. (SCG, III, 70, 2464)

Oagente superior é o agente em virtude de si, isto é, o produtor propriamente do efeito. $\mathrm{O}$ agente inferior é o agente em virtude de outro; é, pois, o propagador. $\mathrm{O}$ primeiro diz respeito ao agente cuja operação própria, isto é, essencial, é causar, por si mesmo, um efeito. $O$ segundo, por sua vez, refere-se ao agente inferior que: (a) recebe do agente superior o princípio para operar por si mesmo; (b) recebe parcialmente o princípio da operação; (c) não recebe o princípio da operação. ${ }^{12}$ No primeiro caso, a atualidade da forma do agente inferior depende do agente superior. Isso se dá para todos os agentes, os quais dependem permanentemente da divindade (cf. SCG, III, 64-65). Quanto ao segundo caso, embora o agente inferior não produza propriamente um determinado efeito, pois não possui, por si

\footnotetext{
${ }^{12}$ Embora o tratamento aqui sobre a relação entre o agente superior, o agente inferior e o efeito enfatize a SCG, Tomás de modo contundente e sucinto trata deste tópico no opúsculo De operationibus occultis naturae.
} 
mesmo, a virtude para produzi-lo, ele pode propagá-lo na medida em que o agente superior conserva em si o princípio da operação, enquanto ocorre a produção do efeito. Nesse sentido, Tomás emprega o exemplo do ar que, quando aquecido, propaga o aquecimento. A respeito desse segundo caso, a seguinte observação deve ser feita: embora não possua a virtude de produzir o efeito, não é contrária à natureza do agente propagá-lo, pois assim procede a partir de uma operação que lhe é essencial. No exemplo do ar, não lhe é contrário aquecer, uma vez que possui, por si mesmo, o princípio do movimento; e, como o aquecimento é um movimento, o ar, mediante o fogo, propaga o aquecimento. Portanto, realizando uma operação que lhe é essencial, $\mathrm{O}$ ar coopera com $\mathrm{O}$ fogo ao propagar $\mathrm{O}$ aquecimento que este produz (cf. ST, Ia, q. 45, a. 5, resp.). Enfim, no terceiro caso, o agente inferior é apenas movido para produzir o efeito, isto é, ele não recebe o princípio do movimento, como ocorre nas operações da técnica .

A partir do exposto, pode-se, então, investigar a relação entre a criação e a propagação:

Tudo o que é causado segundo determinada natureza não pode ser a primeira causa desta natureza, mas é causa segunda ou instrumental. Com efeito, Sócrates, porque tem uma causa de sua humanidade, não pode ser causa primeira da humanidade. Caso contrário, sendo a sua humanidade causada por outrem, dever-se-ia afirmar que ele é causa de sua própria humanidade. Por isso, é preciso que o gerador unívoco seja agente instrumental em relação àquilo que é causa primeira de toda a espécie. E daí também ser preciso que todas as causas agentes inferiores sejam reduzidas às causas superiores como as causas instrumentais o são às causas primeiras. Toda outra substância que não seja Deus tem o ser causado por outrem [...]. Logo, é impossível que ela seja causa do ser, a não ser como causa instrumental e agente em virtude de outrem. Mas o instrumento nunca é usado senão para causar uma coisa por meio de movimento, visto ser da natureza do instrumento ser um movente movido. (SCG, II, 21, 
Nesse texto, mediante a noção de causa instrumental, Tomás expõe a relação entre a operação divina que confere ser e as operações particulares que determinam o ser. Nele é dito que o indivíduo gerado possui característica material e formal, o que é assegurada pela expressão "toda a espécie" (totius speciei). ${ }^{13}$ A característica material, por dizer respeito à matéria prima, compete apenas à divindade produzir. Quanto à característica formal, quando causa e efeito pertencem à mesma espécie, ela não pode ser produzida por essa causa, pois se esse fosse o caso, a causa produziria sua própria forma substancial. Nesse sentido, a carência está na causa, não no efeito, pois o efeito possui a disposição neces-

\footnotetext{
${ }^{13}$ Torna-se necessário esclarecer que a noção de "espécie" é empregada por Tomás em dois registros, nem sempre separados pelo autor: na teoria do conhecimento e na metafísica. No primeiro caso, trata-se de um "ser de razão", ou seja, de algo pertencente exclusivamente aos "dados" internos a qualquer intelecto (divino, angelical, humano). No segundo caso, por seu turno, refere-se as coisas externas ao intelecto humano, ou seja, as coisas do mundo. É no segundo sentido que emprego a noção de "espécie" neste artigo. Por mais paradoxal que pareça, como se perceber pela citação acima de SCG, II, 21, 973, o próprio Tomás afirma que a espécie é causadas pela divindade: "Por isso, é preciso que o gerador unívoco seja agente instrumental em relação àquilo que é causa primeira de toda a espécie" (Et ideo oported quod generans univocum sit quasi agens instrumentale respectu eius quod est causa primaria totius speciei). O caráter de ser "causada", "ser feita", não pode ser interno ao intelecto divino porque a divindade é absolutamente imutável em todos os aspectos possíveis (cf. SCG, I, 14-27). Ademais, se "espécie" denotasse necessariamente "ser de razão", então haveria a produção de conceitos pela divindade, algo vetado por Tomás, pois o conhecimento divino é apenas intuição (cf. SCG, I, 40-71), logo a divindade não causa algo interno a si. Portanto, a expressão totius speciei só pode denotar o caráter de "efeito" da espécie, ou seja, ela é criada pela divindade. E se é criada pela divindade, ela enquanto "efeito divino", com relação ao intelecto divino, não pode ser entendida como "ser de razão". No intuito de evitar a possível confusão entre as duas acepções de "espécie", certos leitores de Tomás empregam caracterizadores, por exemplo, "biológica" ou "real" para tratar da espécie das coisas geradas na natureza (ADLER 1939a, p. 80-122; ADLER 1939b, p. 237-270; ADLER 1939c, p. 381-443; MAURER 2004, p. 491-514; DUMSBAY 2012, p. 371-395.). Tomás às vezes emprega specie creata no contexto das criaturas (cf. SCG, III, 51, 2285; De veritate, q. 8, a. 16, ad 11; De veritate, q. 10, a. 11, resp.; De veritate, q. 20, a. 4 arg. 7; De veritate, q. 20, a. 4 arg. 8; Compendium theologiae, II, 9). O tratamento próprio da espécie criada encontra-se no interior do tratamento metafísico sobre a criação e a conservação do mundo empreendido no Hexameron, ou seja, o tratado sobre o Genesis 1 que diz respeito à obra dos seis dias. Esse tratado está presente no In Sent., II, distinções 12-18, e na ST, Ia, qq. 65-74, e ainda que de modo bastante resumido no De Potentia, q. 4, aa. 1-2.
} 
sária para essa produção, porém, a causa não possui a virtude para tanto. Por outro lado, quando causa e efeito são dessemelhantes especificamente, a causa possui a virtude para produzir a característica formal no efeito, todavia, o efeito é carente, pois não possui a disposição para receber essa operação. Nessa medida, a operação da causa dessemelhante especificamente, porém semelhante genericamente, a geradora equívoca, se configura como a preparação ou disposição do efeito para receber a forma específica, a qual é introduzida pelo gerador unívoco, isto é, a causa eficiente mais diretamente envolvida na geração. Portanto, causado numa espécie, o indivíduo (Sócrates) não pode ser causa primeira da espécie. Todavia, ele é de certo modo causa segunda da mesma, isto é, propaga o ser a partir da espécie, como gerador unívoco, ao introduzir a forma substancial na matéria quando da geração de outros indivíduos, donde ser dito por Tomás que o Sol e o homem (Sócrates) geram outro homem (cf. ST, Ia, q. 118, a. 2, ad3).

A necessidade que o efeito possui do propagador é dita de dois modos, a saber, só no movimento, ou no movimento e na existência. No primeiro modo, o efeito não depende de instrumento para existir, mas apenas para se mover, são os entes subsistentes. Nesse sentido, a divindade cria o efeito e o conserva mediante instrumentos, como é o caso dos astros e da matéria prima:

Se criar só a Deus pertence, é preciso que tudo tenha sido produzido imediatamente por Deus e que não possa ter sido senão por criação. Tais entes são as inteligências [...] que não são compostas de matéria e forma, e semelhantemente, toda matéria corpórea. (SCG, II, 22, 982)

A expressão "toda matéria corpórea" refere-se à matéria constitutiva das regiões supralunar e sublunar, qual seja, a 
matéria prima. Convém esclarecer que Tomás às vezes emprega indistintamente "matéria" e "matéria prima”, uma vez que, tratando-se do efeito da operação divina, ambas possuem o mesmo sentido, qual seja, ente em potência (SCG, II, 16, 942-943). Todavia, quando se referem à região sublunar, denotam estados diferentes. Dizendo respeito à região supralunar, por sua vez, denotam o mesmo estado.

Os sentidos dos estados diferentes na região sublunar dependem do referencial, qual seja, antes ou depois da mistura dos quatro elementos, a saber, fogo, ar, terra e água. Se o referencial for "antes" da mistura, então se emprega "matéria prima” que significa potência pura. Como potência pura, a matéria prima precede por natureza os elementos sob os quais ela é criada, e, é a condição pela qual a existência lhe é atribuída. A noção de potência pura significa a total ausência de ato e, consequentemente, de forma. Logo, há total ausência do princípio de movimento e de tempo, pois é pela forma que um ente possui o ato e o princípio de movimento que é medido pelo tempo. Porém, como não há ente sem forma na natureza, a potência pura da matéria prima diz respeito à consideração desta nela mesma. Essa consideração afirma que, embora por natureza a matéria prima preceda as formas dos elementos nos quais é substrato, a matéria prima não se refere aos elementos (cf. SCG, II, 94, 1815). Portanto, nessa consideração, a matéria prima, por si mesma, é dita informe. Entretanto, ela nunca se encontra sem forma na natureza, uma vez que é o substrato dos elementos (ST, Ia, q. 67, a. 4, ad1). Por outro lado, se a referência for "depois" da mistura, emprega-se "matéria", sendo, nesse sentido, sinônimo de "corpo", ou seja, a agregação, e subsequente mistura, de pelos menos dois elementos. Nesse sentido, enquanto a matéria prima só depende 
da divindade para existir e de outras causas para se mover, os entes que possuem corpo dependem de outras causas para existir e se mover.

\section{NATUREZA COMO PRINCÍPIO DE MOVIMENTO}

No que se refere ao movimento dos corpos, este é compreendido a partir da noção de motor: "Nos movimentos corporais, denomina-se motor aquele que dá a forma, que é princípio de movimento" (ST, Ia, q. 105, a. 5, resp.). ${ }^{14}$ Portanto, dar a forma, isto é, reduzir a potência ao ato, é ser princípio de movimento. Nesse sentido, sendo a forma o princípio da operação, segue-se que tudo que possui forma substancial na natureza se configura como motor, ou seja, pode reduzir a potência ao ato. Sendo assim, o motor é dito princípio em sentido ativo .

Porém, princípio também pode ser dito em sentido passivo:

Com efeito, diz-se que um movimento é natural, não somente por causa de um princípio ativo, mas também devido ao princípio passivo, como se observa na geração dos corpos simples. Estes, portanto, não podem ser ditos naturais devido ao princípio ativo, porque se move naturalmente pelo princípio ativo aquilo cujo princípio ativo é intrínseco, pois a natureza é o princípio do movimento daquilo em que está. Todavia, o princípio ativo da geração do corpo simples é extrínseco. Por isso, não é natural em razão do princípio ativo, mas somente em razão do princípio passivo, que é a matéria, que tem apetite natural para a forma natural. (SCG, III, 23, 2041)

A expressão "princípio de movimento" não é emprega-

\footnotetext{
${ }^{14}$ A expressão "princípio de movimento" é um dos modos pelos quais Tomás compreende a noção de natureza. Tal noção é bastante debatida pela literatura secundária, ver: Mcwilliams 1945; Weisheipl 1955; Weisheipl 1981, p. 81-104; Weisheipl 1982, p. 137-169; Aertsen 1988, p. 279 336; Twetten 1991, p. 235-254; Elders 1994; Twetten 1996, p. 205-243; Lang 1996, p. 411-432.
} 
da apenas para se referir ao motor, ou seja, o princípio dito em sentido ativo. Esta expressão também designa passividade, a saber, quando a potência está disposta para ser reduzida ao ato, razão pela qual o movimento pode ser dito natural tanto em sentido ativo quanto passivo. Ademais, Tomás sustenta que o corpo simples, isto é, cada um dos elementos, não sofre a mudança substancial pelo princípio ativo, ou seja, não é intrínseco ao elemento o princípio ativo da mudança substancial. Nesse aspecto, a mudança substancial do elemento só ocorre na medida em que há um princípio ativo externo que age sobre ele .

Todavia, a noção de princípio nos dois sentidos pode ser atribuída ao motor tendo como referência o próprio motor operando sobre si:

Para que [a inteligência] mova, porém, não é necessário que se una ao corpo como forma, mas pelo contato de virtude, como o motor se une ao móvel. Nesse sentido, Aristóteles no livro VIII da Física, após mostrar que o primeiro que move a si mesmo se compõe de duas partes, das quais uma move e a outra é movida, ao afirmar como as duas partes se unem, sustenta que se unem por contato, seja mútuo, se ambas são corpos, seja de uma com a outra, mas não reciprocamente, se uma é corpo e a outra não. (ST, Ia, q. 70, a. 3, resp.)

De acordo com essa passagem, é preciso primeiro considerar o motor nele mesmo para, subsequentemente, considerá-lo em relação a outro. Se o motor é constituído somente de partes corpóreas, então há o contato corpóreo (contactum corporalis) entre as partes, a movente, ativa, e a movida, passiva, que se tocam pelos extremos das tangentes. Porém, se o motor não somente possui constituinte corpóreo, mas também constituinte não corpóreo, então o contato deste com aquele ocorre virtualmente, ou seja, o constituinte não corpóreo é o próprio poder que reduz a potência do constituinte corpóreo ao ato . 
A justificação dessa noção de "contato de virtude" (contactum virtutis) é fornecida pelo postulado segundo o qual o corpo humano necessariamente possui uma alma imaterial, sendo que ambos são tomados como os constituintes do mesmo motor (ST, Ia, q. 70, a. 3, resp.). Nesse sentido, a alma é capaz de mover o corpo se constituindo como sua operação, isto é, ela atualiza as potências do corpo, como mostra o fato da alma, a partir da concepção, provocar calor no corpo humano informado pela frieza. ${ }^{15}$

Esses sentidos da noção de contato são empregados por Tomás para explicitar a relação entre motores. O primeiro, qual seja, o contato corpóreo, é empregado na explicitação do vínculo entre as regiões supralunar e sublunar. O segundo, por sua vez, o contato de virtude, é empregado na explicação da causalidade eficiente exercida pelas inteligências nos astros.

No que se refere à relação entre as regiões supralunar e sublunar, tratando-se da operação permanente tomada em sentido geral, ou seja, não designando a recepção dessa operação neste ou naquele motor, Tomás, na SCG, II, 29, 1060 sustenta que há sempre operação dos astros sobre a região sublunar:

[...] se Deus quis que o universo fosse feito, devia fazer o Sol e a Lua e coisas semelhantes, sem as quais não poderia haver o universo. [...] se Deus quis que houvesse animais e plantas, devia fazer os corpos celestes, pelos quais seriam aqueles conservados; e se quis que houvesse homem, devia fazer os animais e plantas e coisas semelhantes, das quais o homem precisa para ser perfeito, embora Deus tenha feito estas e aquelas coisas por mera vontade.

\footnotetext{
15 "[...] a matéria corporal obedece à concepção da alma, pois pela concepção da alma o corpo muda do frio para o calor, e em alguns casos até dá saúde para a enfermidade”. (ST, Ia, q. 110, a. 2, obj. 1).
} 
Os entes compostos de forma e da matéria resultante da agregação dos elementos, quais sejam, os entes da região sublunar, animais, plantas e homens, dependem, para a existência e o movimento, da conservação, isto é, da manutenção dessa agregação. Nessa medida, esses entes existem e se movem somente enquanto dura a conservação da agregação dos elementos. Para tanto, necessitam da operação de outras causas, sobretudo dos astros .

A maneira pela qual os astros conferem movimento aos entes sublunares é explicitada na SCG, II, 22, 985:

A toda potência passiva corresponde alguma potência ativa, pois a potência está para o ato como a matéria está para a forma. Assim, não pode o ente em potência conseguir tornar-se ato senão pela virtude de alguma coisa que existe em ato. Seria, pois, supérflua a potência se não houvesse a virtude ativa do agente que a pudesse reduzir a ato. Todavia, nada há de supérfluo nas coisas da natureza. Por esse modo, vemos que tudo que há na potência da matéria das coisas geráveis e corruptíveis pode ser reduzido a ato pela virtude ativa que há no corpo celeste que é o primeiro agente da natureza.

Conforme esse texto, a redução da potência no efeito só ocorre porque essa potência encontra-se atualizada na causa, isto é, o que é atualizado no efeito, preexiste em ato na causa. Dito de outro modo, sejam semelhantes específica ou genericamente a causa possui em ato aquilo que o efeito possui em potência. No caso dos astros com relação à região sublunar, a semelhança é genérica. Nesse sentido, o conjunto dos astros, o céu ou corpo celeste, é denominado de primeiro agente da natureza (primum activum in natura), porque ele mantem uma condição necessária para que haja mudança substancial, a saber, o movimento retilíneo que os elementos realizam, resultando na agregação, quando ocorre a geração, ou na segregação, quando ocorre a corrupção. Este movimento é causado, sobretudo pelo Sol e pela Lua, 
na medida em que eles, a partir do movimento rotacional em torno de seus próprios eixos, propagam luz à região sublunar e, assim, ocorre o contato corpóreo entre as regiões (ST, Ia, q. 67, a. 3, resp.) .

No que diz respeito à noção de contato de virtude empregada para explicar a causalidade eficiente das inteligências sobre os astros, esta se dá mediante a consideração das noções de matéria e forma atribuídas aos astros:

Como o corpo celeste tem o movimento natural distinto do movimento natural dos elementos, segue-se que a natureza daquele é diferente da natureza dos quatro elementos. Ademais, como o movimento circular próprio dos corpos celestes não implica contrariedade, e os movimentos dos elementos são contrários entre si, opondo-se o que sobe ao que desce, segue-se que os corpos celestes são sem contrariedade. E, também, como a corrupção e a geração são de contrários, segue-se que, por sua natureza, os corpos celestes são incorruptíveis, os elementos, porém, corruptíveis. [...] a matéria do corpo celeste, em si considerada, está em potência apenas para sua própria forma, seja ela qual for, alma ou qualquer outra coisa. Por isso, a forma completa a matéria, de tal modo que na matéria não permanece potência alguma para o ser, mas somente para o lu$\operatorname{gar}[$....]. (ST, Ia, q. 66, a. 2, resp.)

A relação entre as inteligências e os astros não se configura como a relação das partes do mesmo motor, mas, sim, como a relação de motores por si mesmos constituídos, sendo, portanto, ontologicamente distintos. Para sustentar essa posição, Tomás se baseia na noção de contato de virtude e, ademais, na constatação segundo a qual a alma do homem move seu corpo. Quanto à noção de contato de virtude, esta é designada pelo verbo "atingir" (attingo). Nessa medida, a noção de contato de virtude não se emprega apenas para explicar a relação entre os constituintes de um mesmo motor, sendo um material e o outro imaterial, mas também para explicar a relação entre motores, na qual um é 
constituído de forma e ato, a inteligência, e o outro de forma e matéria, o astro. No que diz respeito ao movimento local do corpo realizado pela alma humana, Tomás faz a seguinte constatação: pode ocorrer que o movimento do corpo seja consequência da concepção da alma, a saber, quando o movimento, mediante o conhecimento prévio, é teleologicamente orientado (ST, Ia, q. 70, a. 3, resp.). Nesse sentido, as inteligências movem diretamente os astros (cf. SCG, III, 23).

Do exposto, segue-se que o movimento e as mudanças da região sublunar não têm as inteligências como os primeiros agentes:

Todo agente produz de algum modo efeito semelhante a si. Todo agente age enquanto ato; por isso, produzir o efeito por alguma introdução da forma na matéria pertence àquele agente que está em ato pela forma que lhe é inerente e não por toda a sua substância. [...] as coisas materiais, que tem formas inerentes à matéria, são geradas por agentes materiais com formas inerentes à matéria, não pelas formas subsistentes. (SCG, II, 16, 937)

As formas subsistentes referem-se às inteligências que, por serem imateriais, são designadas como separadas. Nessa medida, as inteligências não podem ser designadas como geradoras, nem unívocas, nem equívocas, uma vez que é a matéria que garante o mínimo de semelhança entre os entes. Portanto, há uma dessemelhança, tanto específica, quanto genérica, que as impedem de estarem envolvidas diretamente na mudança substancial. Nesse sentido, Tomás concorda com a crítica que Aristóteles faz a Platão, qual seja, uma forma subsistente, embora cause diretamente o movimento celeste, não causa diretamente a mudança substancial na natureza (SCG, III, 69, 2449). 


\section{CONSIDERAÇÕES FINAIS}

A negação de que as inteligências são causas da mudança substancial é sustentada porque a mudança substancial requer que a causa eficiente se envolva diretamente com a atualização de potências no efeito, isto é, que a causa possua semelhança específica ou genérica com o efeito, o que é assegurado a partir da noção de redução. Porém, não somente a mudança substancial é explicitada pela noção de redução. Com efeito, a causalidade que pertence à cosmologia de Tomás está centrada nessa noção. Isso se verifica, sobretudo, na consideração dos entes subsistentes. No caso da matéria prima, os argumentos de Tomás que visam sustentar que ela é efeito da operação divina de criação, sempre partem deste princípio: a causa do todo é a causa das partes (cf. SGC, II, 17, 954). Isso significa que Tomás quando trata da matéria prima como efeito, sempre tem como referência os entes naturais já constituídos. Nesse sentido, se a divindade é a causa de todo o ente, ela será a causa de suas partes. Como a matéria prima é constituinte do ente natural, então a divindade é a causa da matéria prima (ST, Ia, q. 44, a. 2, resp.). Do mesmo modo ocorre com os argumentos que sustentam que os astros e as inteligências são efeitos, a saber: parte-se do efeito em busca da causa, isto é, pela redução. Nessa medida, "como" isso ocorre não é acessível à razão, pois, neste caso, seria preciso partir da causa em direção ao efeito. Dito de outro modo, seria necessário conhecer a divindade nela mesma, essencialmente, uma impossibilidade que, para Tomás, já está estabelecida (cf. SCG, I, 14-27).

A redução, nesse contexto, se dá em dois procedimentos: da arte para a natureza; da natureza para a divindade: 
[...] se alguém faz alguma coisa de outra, aquela da qual faz é pressuposta à ação de quem faz e não é produzida por tal ação. Assim o artífice opera com as causas naturais, por exemplo, a madeira e o ar, que não são causados pela ação da arte, mas pela da natureza; por sua vez, a própria natureza causa os seres naturais quanto à forma, mas pressupõe a matéria. Se, pois, Deus não atuasse senão sobre algum pressuposto, seguir-se-ia que esse pressuposto não foi causado por ele. Pois já mostramos antes (q. 44. a. 1,2) que nada pode existir nos seres que não provenha de Deus, causa universal de todo ser. Donde é necessário dizer que Deus traz, do nada, as coisas ao ser. (ST, Ia, q. 45, a. 2, resp.)

primeiro procedimento de redução parte da arte em direção à natureza. Nele, o artífice é considerado como a causa extrínseca da produção de uma forma artificial: um objeto de arte determinado. Para tanto, o artífice se utiliza dos meios naturais para a fabricação, a madeira e o ar. A madeira e a forma deste ar que o artífice faz uso são produzidas pela operação da natureza. Nesse sentido, a natureza se configura como causa intrínseca da produção de formas na madeira e no ar.

Comparando a ação do artífice com a operação da natureza, a operação da natureza é mais perfeita porque a ação do artífice pressupõe a operação da natureza que dispõe a matéria para o artífice. Todavia, num segundo procedimento de redução, chega-se ao postulado de acordo com o qual a natureza produz as formas. Essa produção tem o céu como o primeiro agente, e pode, em algumas circunstâncias, ser teleologicamente orientada pelas inteligências (SGC, III, 22 , 2028). Ademais, a matéria prima é pressuposta nessa produção, uma vez que a natureza é compreendida como causa das formas naturais e não de todo o ente. Nessa medida, chega-se, enfim, a afirmação segundo a qual a divindade cria a matéria prima e a dispõe para a operação da natureza. Por conseguinte, a divindade não anula a opera- 
ção da natureza (SCG, III, 69, 2442), o movimento e as mudanças, pois esta lhe serve de instrumento, tampouco a natureza é autossuficiente em sua operação, pois pressupõe a operação divina. Portanto, Tomás estabelece a relação de causas subordinadas essencialmente de modo que a operação de uma não subtraia a operação de outra. Isso se dá, como explicitado, por uma dupla consideração. Uma referente à essência do ente. Outra dizendo respeito à operação deste. Sendo assim, Tomás evidencia que um ente pode necessitar de outro quanto à essência, mas ser autônomo quanto à operação. Nessa medida, todos os entes necessitam, quanto à essência, da operação divina de criação. Porém, isso não os priva de operar de modo autônomo e, ademais, de uns necessitarem de outros, como ocorre, no caso apresentado, da região sublunar que necessita da contínua locomoção do céu. Aliás, negar essa necessidade é, para Tomás, um sério equívoco filosófico decorrente de uma compreensão equivocada das noções de criação e natureza, pois elimina duas teses muito caras à cosmologia: "a providência divina impõe ordem a todas as coisas (divina providentia ordinem omnibus rebus imponit)" (SCG, III, 81 2571); "os corpos celestes movem e regem os corpos inferiores (corpora caelestia sunt motiva et regitiva inferiorum corporum)" (SCG, III, 82 2576). O movimento e a regência do céu sobre a região sublunar, conforme a primeira tese citada, decorre da imposição da ordem da providência divina, sendo a negação dessa imposição, portanto, um absurdo para a filosofia. Sendo assim, a quarta proposição condenada em 1270, mesmo que tivesse a intenção de não enfraquecer o poder divino, afirma, aos olhos de Tomás, um absurdo, pois indica que haveria operação do fogo se o céu repousasse. 
Se o promulgador das condenações de 1270 temia que a necessidade apontada enfraquecesse o poder divino, era porque em sua concepção de mundo e de natureza, talvez, faltasse uma concepção de causalidade que vinculasse criação e natureza de tal modo que, dentre os entes naturais, houvesse subordinação essencial no operar, como sustenta Tomás. É justamente porque possui uma cosmologia baseada numa causalidade que articula criação e natureza que Tomás se mantém conceitualmente contra a condenação, pois como nada há de supérfluo na natureza (cf. SCG, II, $22,985)$, sendo ela efeito divino, então ela impõe necessidade sobre os entes naturais, mas não na divindade porque a causa é mais excelente do que o efeito.

Abstract: Aquinas' conception of causality, especially when associated to the notions of creation and nature, grounds his cosmology as presented in the Summa contra gentiles. Two theses are central to this cosmology. The first claims that the divine causality bestows order upon the world. The second in turn maintains that the set of stars, the heaven, rules and moves the sublunar realm, which necessarily occurs due to divine causality. There is therefore an articulation conceived by Aquinas between the two theses. To show this articulation is the aim of this paper. For this, I investigate how Aquinas understands and associates the notions of causality, creation and nature in such a way that it guarantees both divine creation and the operation proper to natural beings, among which stands out the heaven, which, in virtue of continuous locomotion, sets the condition for the actualization of beings' potentialities.

Keywords: causality; creation; nature; cosmology.

\section{REFERÊNCIAS}

ADLER, Mortimer J. Problems for Thomists: I. The Problem of Species (Part One). The Thomist, 1939a, p. 80-122.

. Problems for Thomists: I. The Problem of Species (Part Two). The Thomist, 1939b, p. 237-270. 
. Problems for Thomists: I. The Problem of Species (Part Three). The Thomist, 1939c, p. 381-443.

AERTSEN, Jan A. Nature and Creature: Thomas Aquinas's Way of Thought. Leiden: Brill, 1988.

BAZÁN, B. Carlos. The Doctrine of the Creation of the Soul according to Thomas Aquinas. In: EMERY, Kent; FRIEDAM, Jr. Russell L.; SPEER, Andreas (eds.). Philosophy and Theology in the Long Middle Ages: A Tribute to Stephen F. Brown. Leiden: Brill, 2011. p. 515-569.

DUMSBAY, Travis. Is there still hope for a scholastic ontology of biological species? The Thomist 76, 2012, p. 37195.

ELDERS, Leo J. La philosophie de la nature de Saint Thomas d'Aquin: philosophie générale de la nature, cosmologie, philosophie du vivant, anthropologie philosophique. Paris: Pierre Téqui, 1994.

GRANT, Edward. Medieval and Renaissance scholastic conceptions of the influence of the celestial region on the terrestrial. The Journal of Medieval and Renaissance studies, v. 17, 1987, p. 1-23.

LANG, Helen S. Thomas Aquinas and the Problem of Nature in Physics II, 1. History of Philosophy Quarterly, v.13, n. 4, 1996, p. 411-432.

MCWILLIAMS, James A. Physics and philosophy: a study of Saint Thomas' commentary on the eight books of Aristotle's Physics. Washington, D.C.: Catholic University of America, 1945. 
SANTOS, Evaniel Brás. Criação e Cosmologia na Summa contra gentiles de Tomás de Aquino. Campinas, IFCHUNICAMP. Dissertação de mestrado, 2013.

THOMAE AQUINATIS. Pars prima Summae Theologiae a quaestione I ad quaestionem XLIX. Opera omnia iussu impensaque Leonis XIII P.M. edita, vol. IV. Roma: Typographia Polyglotta, 1888 .

- Pars prima Summae Theologiae a quaestione L ad quaestionem CXIX. Opera omnia iussu impensaque Leonis XIII P. M. edita, vol. V. Roma: Typographia Polyglotta, 1889 .

- Summa contra gentiles. Ed. Leon., vol. XIII-XV. Roma, 1918-1930.

- Quaestiones disputatae de Potentia Dei. Ed. P. MANDONNET, vol. II, Parisiis: P. Lethielleux, 1925.

- Scriptum Super Libros Sententiarum Magistri Petri Lombardi. Ed. P. Mandonnet t.1, t.2, Parisiis: P. Lethielleux, 1929.

. Compendium theologiae seu Brevis compilatio theologiae ad fratrem Raynaldum, pars II: De spe [ed. G. de Grandpré]. Ed. Leon., vol. XLII. Roma: Editori di San Tommaso, 1979.

. Quaestiones disputatae de Veritate. Ed. A. Dondaine. Ed. Leon., vol. XXII.1-3. Roma: Editori di san Tommaso, 1972-1976.

. De operationibus occultis naturae. Opera omnia iussu Leonis XIII P. M. edita, vol. XLIII, Roma: Editori di San 
Tommaso, 1976.

. Summa contra gentiles. Roma: Marietti, 1961-1967.

. Suma de Teologia (11 vols.). Trad. Alexandre Correia. Livraria Sulina Editora,1980.

- Super Boetium De Trinitate. Opera omnia iussu Leonis XIII P. M. edita, vol. L. Roma-Paris: Éditions du Cerf, 1992.

. Suma contra os gentios (2 vols.). Trad. D. Odilão Moura, O.S.B. Sulina; Edipuc-RS, 1993.

TORRELL, Jean-Pierre. Iniciação à Santo Tomás de Aquino: sua pessoa e obra. São Paulo: Loyola, 2004.

TWETTEN, David B. Back to Nature in Aquinas. Medieval Philosophy and Theology, v. 5, p. 205-243, 1996.

. Why Motion Requires a Cause: The Foundation for a Prime Mover in Aristotle and Aquinas. In: LONG, James (ed.). Philosophy and the God of Abraham: Essays in Memory of James A. Weisheipl. Toronto: Pontifical Institute of Mediaeval Studies, 1991. p. 235-254.

WEISHEIPL, James A. Nature and Gravitation. River Forest, Illinois: Albertus Magnus Lyceum. 1955.

- Friar Thomas D'Aquino: his Life, Thought and Works. Toronto: Pontifical Institute of Medieval Studies, 1975.

.The Spector of Motor Coniunctus in Medieval Physics. In: MAIERÙ, A; BAGLIANI, A. Paravicini (eds.). Studi sul XIV secolo in memoria di Anneliese Maier. 
Roma: Edizioni di storia e letteratura, 1981. p. 81-104.

- Aristotle's Concept of Nature: Avicenna and Aquinas. In: ROBERTS, Lawrence (ed.). Approaches to Nature in the Middle Ages. Binghamton, New York: Center of Medieval \& Early Renaissance Studies, 1982. p. 137169. 